\title{
Hero and Villain Representation in the "Spiderman" Movie by Sam Raimi
}

\author{
Candra Juanda ${ }^{1 *)}$, Tahrun $^{1}$, Mulyadi $^{1}$ \\ ${ }^{1}$ Universitas PGRI Palembang, Indonesia \\ "Corresponding author. Email: canjunbaturaja2018@gmail.com
}

\begin{abstract}
This research is concerned with Hero and villain presentation in the Spiderman movie by Sam Raimi, the intrinsic elements on the Spiderman movie by Sam Raimi The implication on learning and teaching of hero and villain are delivered the Spiderman movie by Sam Raimi. The descriptive qualitative method was used by the author, along with a data analysis approach. Plot, character, setting, point of view, and theme are examples of intrinsic elements. The impact of the Spiderman movie by Sam Raimi on learning and teaching of the hero and villain was that the dialogs from the movie clip clarified their emotions and gave them the right words to express their thoughts. The movie clip approach, when used with high school and college teachers, will increase faculty instruction and encourage professional development. When faculty teach alone, they face difficulties.
\end{abstract}

Keywords: Hero, Villain, Spiderman

\section{INTRODUCTION}

Language is one of the main parts in life. Language, communication and human beings are three components that cannot be separated from each other. Language is extremely important in our daily lives. People use at least one language to communicate and express their thoughts, desires, and emotions to others during the communication process. According to Chaer and Agustina [1] language allows one to communicate with others, express one's desires, feelings, and ideas.

Language, according to Edward in Basuni [2] is is "a guideline to social truth, so the living creatures would be at the expense of the word that has become the means of speech for their society". Language is a psychological phenomenon as well. It is a means of communication between people that brings them into contact with their surroundings.

People's communication language is affected by social factors. Social status, education, age, socioeconomic status, profession, and a variety of other factors are examples. Jhonson [4] Formal paraphrase ss a result, language and culture are inextricably linked. They have a close friendship because they both support one another. A society living in a specific area is usually divided into smaller groups. They are defined by ethnicity, profession, religion, philosophy, socioeconomic status, education, and other factors.

Nowadays in the developing era, the relation and communication among nations become very significant in order to interlace fellowship and cooperation. From the various languages in the entire world, English languages and become the international language. However, not everyone, particularly in Indonesia, can use and communicate in English fluently. Furthermore, it becomes impossible for them to grasp the meaning. Furthermore, understanding the concept and meaning has become difficult for them. That is why the translators and interpreter take the significant role to prevent misunderstanding in the communication among speakers in different language. So, communication being limited. In other word, they must learn English and comprehend English well. To help beginners understand English, they should use media to learn. Newspapers, movies, novels, and books are all examples of media. The movie is an example of audiovisual media. It is the most popular medium for beginners to learn English. It's entertaining and enjoyable.

For some people, watching movies has become a part of their daily lives. People watch movies for a variety of reasons, including relaxation, entertainment, gaining knowledge and understanding, mastering a different language, and attempting to comprehend certain societies Regardless of their life circumstances, history, gender, or age, most people enjoy watching movies. Movies are watched in not only the metropolitan areas, as well as in tiny cities. Individuals can now watch movies whenever and wherever they want thanks to advances in technology such as the internet and smartphones. A movie, also known as a motion picture, is a new form of visual art that has emerged during the last three centuries. 
That is a difficult to define dynamic, one-of-a-kind art form, however the feature of cinema is instant and basic. In reality, films were also a form of art and a means of entertainment media, with the latter having a significant sociological effect. Furthermore, they have a scientific and technological background [5]. A film portrays a narrative or conversation upon on display. A film made by greatest invention to cams or by creating pictures with motion graphics. The majority of movies are based on true stories from around the world, while the rest are based on films or novels. Spiderman, Harry Potter, Twilight, and The Lord of the Rings are just a few examples of films based on novels. According to Christopher [6], the film contains lines of dialogue and portrays apparent character developments that explicitly convey significance to the audience.

Explicit material is probably some kind of "key thing" or cultural mindset expressed explicitly by the director through the characters' mouths and acts. People can be taught morally, educationally, socially, culturally, and in other ways by watching movies. If we seek to comprehend the film then turn our attention, we will gain knowledge, learning, and motivation. A film is a visual medium which could educate and increase public's understanding of a specific topic.

According to Bogdan, et al [7], A film should display the viewer a picture and therefore clearly introduce them to the audience. The majority of viewers clearly interact with the film's themes, and others struggle to interact. Another of the film's themes is about the hero and the villain.

Spider-Man is a 2002 American superhero film based on the same-named Marvel Comics character. It is the first instalment in the Spider-Man trilogy, directed by Sam Raimi from a screenplay by David Koepp, and stars Tobey Maguire as the title character, alongside Willem Dafoe, Kirsten Dunst, James Franco, Cliff Robertson, and Rosemary Harris. A story revolves around Peter Parker, the introvert teenage intellect that gains spider-like mutant powers after becoming infected by such a genetic modification insect. Since the adoptive dad is murdered by an armed assailant, a jealousy Parker is compelled to use his newfound abilities for a higher cause, also as champion SpiderMan, and exact revenge to the uncle's assassination. Parker's efforts in manage the private affairs when him finishes school then works as a photojournalist whilst also dealing through the education, the lifelong closest friend Harry Osborn, the increasing emotions towards his former school crushing Mary Jane Watson, even the double role as Spider-Man.

Spider-Man premiered on April 29, 2002, at the Mann Village Theatre, and was made public four days later, on May 3, in the United States. Critics and fans lauded Raimi's direction and sound, the faithfulness and commitment to the Spider-Man mythos, this same fight scenes, special effects, Danny Elfman's sound track, and the cast's performances, mostly Dafoe and Maguire. The movie was a commercially successful, being the first to gross $\$ 100$ million in a single weekend and the most profitable comic-book-based film at the time.

Direct health power, intellect, diverse analytical abilities along with gun shooting, sexual prowess, imagination, bravery, upper class existence, divine favour or ancestry, money, but also ideological righteousness may all be sources of strength for heroes. Further than the person, power may be derived by masses of people or from the human structures used to motivate anyone. Heroes with one form of power frequently clash with heroes who've had others, including such physical strength versus intellect, and heroes with one type of power frequently battle to superheroes who've had someone else.

Heroes is malicious and strong enough just to threaten anyone, heightening the need to avoid themselves. In political rivalry, fear and hatred of heroes are powerful emotions [8].

\section{METHODS}

The descriptive qualitative method was used by the author, along with a method of data processing. The methodological research is applied, with data collected using terms or photographs instead of just numbers [9]. The writer deduces from this observation that methodological analysis is a method of analysing data that is as similar to narrative type as practicable, and so the scientific method is really significant in the descriptive method.

\section{RESULTS AND DISCUSSION}

The notion of hero and villain is a character structure that is widely used in literature and cinema, but it appears that since the mid-1990s, there has been a surge in growth or deviation from the classical structure of building hero and villain as unambiguous in big budget Hollywood film production. Why and how are Hollywood films shifting their approach to character development, and does this reflect a particular cultural fascination? In this thesis, it was argued that the relevance of this character construction is critical to audience reception and, as a result, the increasing popularity of this structure [9].

In Spiderman, the same theme of sacrifice serves as a dividing factor between hero and villain, serving as the gap between them that eventually divides them and causes the film's tension and inherent conflict. Elijah Price (Samuel L. Jackson) kills a large number of people in his search for the hero and the moral good, basically as a means of making meaning for himself while also saving more people than he originally sacrificed. Spiderman and Batman can be argued to be the defining two examples that have formed the template for ambiguous villains in subsequent superhero films, and thus it is highly important to connect them to 
the newest blockbuster edition to this type of film. Spiderman has the same ambiguous villain character as Andersen, as well as the theme of sacrifice, which is illustrated throughout the film by both the heroes and the villain [10].

\section{CONCLUSION}

Spider-Man reveals Peter Parker's tale, who becomes Spider-Man after being bitten by a spider as a hero, when he is in a laboratory looking at spider species, as seen in [10]. He has spider-like superpowers, and as a result of those abilities, he is able to save others in perilous situations, detect villains or potential hazards, and prevent crimes. In this film, Spider-Man must also contend with Dr. Otto Octavius, also known as Dr. Octopus, as the main antagonist who has wreaked havoc on New York City as a result of his failed experiment. Dr. Octopus is able to stop crimes and save people in the city of New York by identifying villains and potential hazards. When Spider-Man has to deal with villains and Dr. Octopus as the principal enemy, he must take action. Triumph, at least in a moral or physical sense, occurs when Spider-Man is able to stop the train and save the girl from the fire before any deaths occur.

\section{ACKNOWLEDGMENTS}

Our deepest gratitude goes to English Department, PGRI University of Palembang, Chancellor of Palembang PGRI University, Director of the Postgraduate Program of PGRI Palembang University and the Education Management Study Program of PGRI Palembang University, who have supported us in doing this extraordinary thing. This project is funded independently. We also want to thank our Education Management friends who helped us a lot in a short time frame to complete this project.

\section{REFERENCES}

[1] Chaer, A., \& Agustina, L. (2015). Sosiolinguistik: Suatu Pengantar [Sociolinguistics: An Introduction]. Jakarta: Rineka Cipta.

[2] Basuni. (2010). Correlation between Local Language and the Students Achievement in English Subject. Journal: Unpublished.

[3] Alexander, J. (2010). The Performance of Politics. New York: Oxford University Press.

[4] Jhonson, A. (2016). Practical Communiation Skill. Bandung: Elex Media Komputindo.

[5] Webster. (2011). Third new international dictionary. Encyclopedia Britania: Meriam Webster Inc.

[6] Christopher, D. (2012). Literary Theory. Great Britain: Pocke Essential.
[7] Bogdan., Robert, C. \& Bikken, S. K. (2013). Qualitaive research for education: An introduction to theory and methods. Boston: Allyn and Bacon.

[8] Dower, J. (2016). War without Mercy. New York: Pantheon Books.

[9] Cohen, L. (2017). Research Method in Education. British Library.

[10] Sandelowski, M. (2010). Focus on research methods whateve happened to qualitative description. Research in Nursing \& Health. 23, 334-340. 